\title{
Health measurement for care management using the international classification of functioning codes
}

\author{
J Okochi ${ }^{1,2^{*}}$, K Takamuku' ${ }^{1}$, T Takahashi ${ }^{3}$ \\ From 26th Patient Classification Systems International (PCSI) Working Conference \\ Munich, Germany. 15-18 September 2010
}

\section{Introduction}

Case-mix systems for rehabilitation and geriatric care require information about a patient's functioning. In PCSI 2009, the author presented newly constructed health-measurement scales for elderly persons using the ICF codes. This year, the author presents a method for case-management using ICF-based health-measurement scales in geriatric rehabilitation facilities.

\section{Methods}

To construct a care-management tool based on the ICF, we developed 12 ICF-based health-measurement scales including basic behavior, mobility, orientation, communication, cognitive activities, eating function, eating behavior, toileting, bathing, oral hygiene, self-care and clothing.

The new scales have the following characteristics:

1. ICF codes are selected using the Rasch method. Therefore, the items included in the assessment scales are unidimensional and independent of measurement settings.

2. By hierarchically rearranging the items in the assessment scales, the authors constructed Guttman scales. Each Guttman scale is composed of four ICF items, dividing their functioning into five categories. This means that each scale includes only four ICF items, making the measurement simpler and less time consuming.

3. By adding illustrations, the user can identify the functional status of patients.

\section{Results}

The case-management tools are as follows:

1. Patients are assigned to one category in each scale.

2. In each scale, the case manager decides whether the patient is more likely to experience an improvement or a worsening of their functional level.

3. If the patient is more likely to improve, an intervention plan, such as rehabilitation or medical intervention, is decided upon. In the case of a patient's worsening, a risk management plan is selected.

\section{Conclusions}

When we use conventional ADL assessments, such as FIM or the Barthel index, users can only determine whether they require help for a certain level, such as bed transfer or toileting. With these new tools, we can now have a clear image of whether patients require rehabilitation intervention for improvement, or risk management for preventing a future worsening of their functioning. This was achieved by hierarchically rearranging ICF items and constructing Guttman-type scales according to the item difficulty using the Rasch model.

Therefore, the new ICF-based health-measurements have the following characteristics:

1. A method to simply describe elderly functional level

2. A method to provide standardized care

3. A method to measure change

By using ICF as common taxonomy, these scales are internationally valid and ready to be used as assessment scales worldwide in a geriatric-care setting. In addition, we can now better understand and manage patient care using functional information based on the ICF.

1Japan Association of Geriatric Health Service Facilities, Tokyo, Japan

Full list of author information is available at the end of the article 


\section{Author details}

${ }^{1} J a p a n$ Association of Geriatric Health Service Facilities, Tokyo, Japan.

${ }^{2}$ Tatsumanosato Geriatric Health Facility, Daito Osaka, Osaka, Japan.

${ }^{3}$ Department of Health Service Management, International University of Health and Welfare, Tokyo, Japan.

Published: 6 October 2010

doi:10.1186/1472-6963-10-S2-A3

Cite this article as: Okochi et al:: Health measurement for care

management using the international classification of functioning codes.

BMC Health Services Research 2010 10(Suppl 2):A3.

Submit your next manuscript to BioMed Central and take full advantage of:

- Convenient online submission

- Thorough peer review

- No space constraints or color figure charges

- Immediate publication on acceptance

- Inclusion in PubMed, CAS, Scopus and Google Scholar

- Research which is freely available for redistribution

Submit your manuscript at www.biomedcentral.com/submit
C Biomed Central 